\title{
Balloon recanalisation of a chronically occluded left internal mammary artery graft
}

\author{
Vivek K Mehan, Bernhard Meier, Philip Urban
}

\begin{abstract}
A patient in whom balloon recanalisation of a chronically occluded left internal mammary artery graft was successful is described. A Magnum-Magnarail system was used, and a four month follow up showed no restenosis.
\end{abstract}

(Br Heart f 1993;70:195-197)

Internal mammary artery grafts have stenosis or occlusion rates of up to $9 \%$ within 22 months of surgery. ${ }^{1}$ Internal mammary angioplasty has been described as an alternative to repeat surgery in patients with recurrent ischaemia after coronary bypass grafting. ${ }^{23}$ Whereas several reports have described balloon recanalisation of occluded saphenous venous grafts, ${ }^{45}$ this is a first description of a successful angioplasty of a chronically occluded internal mammary artery graft.

\section{Case report}

A 59 year old man presented with persistent angina after coronary artery bypass surgery performed five months earlier. $\mathrm{He}$ had received a left internal mammary artery graft to the left anterior descending coronary artery and saphenous vein grafts to the first marginal branch of the left circumflex coronary artery and the posterior descending branch of the right coronary artery. His resting electrocardiogram was normal, and a bicycle stress test was positive for ischaemia $(1.5 \mathrm{~mm}$ down sloping ST depression in leads V4-V6 at $50 \mathrm{~W})$. Coronary angiography confirmed the lesions known from before surgery, namely the occlusion of the left anterior descending coronary artery distal to its first diagonal branch, $60 \%$ stenosis of the first marginal branch of the left circumflex artery, and occlusion of the posterior descending branch of the right coronary artery. The left internal mammary artery graft appeared as a narrow vessel that was occluded in its midsegment (fig 1A). The saphenous vein graft to the left circumflex coronary. artery was occluded at its origin; the graft to the posterior descending coronary artery was patent.

Balloon recanalisation of the left internal mammary artery was performed with a 7 French internal mammary guiding catheter (Schneider, a foreshortened version to allow for the increased distance between guiding catheter tip and the lesion). The occlusion was crossed with a 0.021 inch Magnum guide wire braced by a $2.5 \mathrm{~mm}$ Magnarail balloon
(Schneider), which was advanced fully to the tip of the wire to allow for greater pushability ${ }^{6}$ (fig 1B). After the first passage of the wire, a diffuse narrowing of the left anterior descending coronary artery distal to the anastomotic site of the internal mammary artery graft was seen (fig 1C). A total of eight dilatations, from one to four minutes in duration with pressures up to $10 \mathrm{bar}$, were performed at the stenotic sites. The final angiogram showed a satisfactory result (fig 1D). No attempt was made to dilate the stenosis of the first marginal branch of the circumflex artery at this time, as the patient's symptoms were attributed to the left anterior descending coronary artery.

The patient had an uneventful stay in hospital, and became symptom free. A bicycle stress test performed one week later showed $1 \mathrm{~mm}$ ST depression in V4-V6 leads at $100 \mathrm{~W}$ and a thallium study showed a small area of reversible anterolateral ischaemia that was attributed to the stenosed marginal branch of the circumflex artery.

The patient continued to be symptom free but the stress test remained positive. A repeat diagnostic study four months later showed no evidence of restenosis of the left internal mammary artery graft or the left anterior descending artery (fig 2). The first marginal branch of the circumflex artery was successfully dilated at this time. A follow up stress test was negative for inducible ischaemia at $150 \mathrm{~W}$.

\section{Discussion}

Stenosis of the internal mammary artery graft usually accurs at the distal anastomotic site. Occasionally it can be located in the body of the graft where it is attributed to injury to the pedicle at the time of surgery. ${ }^{78}$ Angioplasty of the stenosis of the internal mammary artery graft is an established mode of treatment with procedural success rates of up to $94 \%$ and good long term clinical improvement. ${ }^{9-11}$ Recanalisation of a totally occluded internal mammary artery graft has not been reported.

Our patient had a left internal mammary artery graft anastomosis to an occluded left anterior descending coronary artery. This graft probably occluded soon after surgery due to sluggish flow induced by the stenoses distal to the anastomosis. These stenoses had not been apparent on the presurgical angiogram, as the left anterior descending coronary artery was filled only by collaterals at that time. After angioplasty, not only was the chronically occluded graft recanalised, but
University Hospital V K Mehan

B Meier 
Figure 1 (A) Left internal mammary artery angiogram in a lateral view, showing an occlusion in the mid segment of the graft (arrow).

(B) Recanalisation with Magnum guide wire, supported by a $2.5 \mathrm{~mm}$

Magnarail balloon (arrow points to balloon marker). (C) Angiogram after first passage of the Magnum wire, showing a

recanalised internal mammary artery graft with distal stenoses of the left anterior descending coronary artery.

(D) Final angiogram showing a recanalised left internal mammary artery graft with good run off into a widely patent left

anterior descending coronary artery.
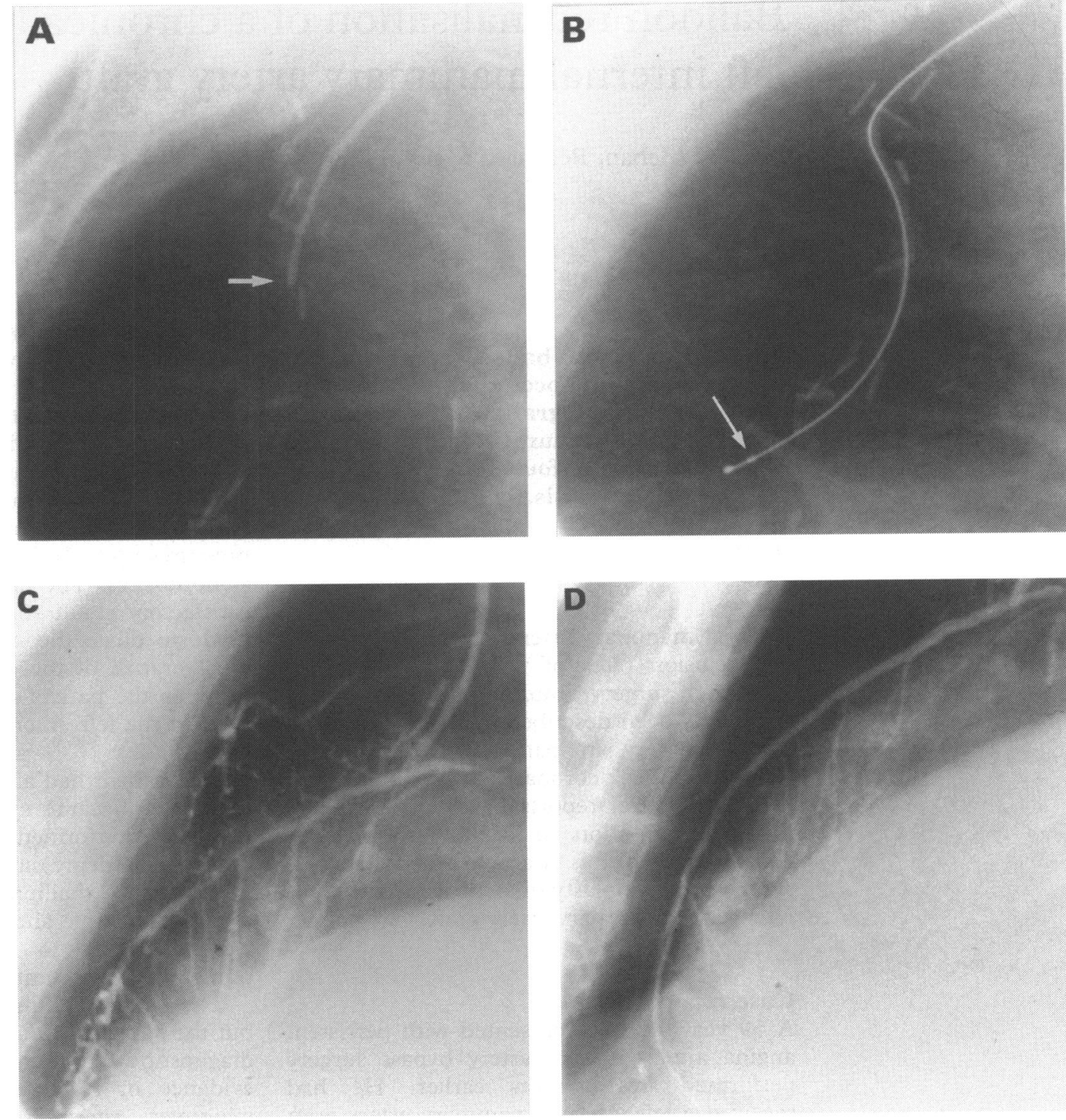

the distal stenoses were also dilated, thus good distal run off was achieved and so the chances of graft patency were enchanced.

The Magnum wire may have some advantages over conventional coronary guide wires for such cases. ${ }^{6}$ Firstly it offers substantial

Figure 2 Follow up angiogram four month later, showing a widely patent graft with good distal run off and no restenosis.

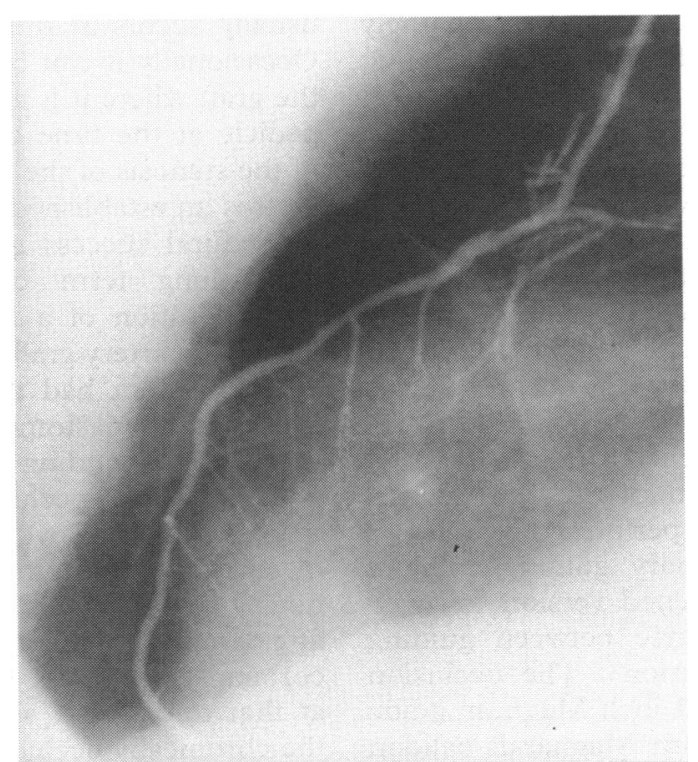

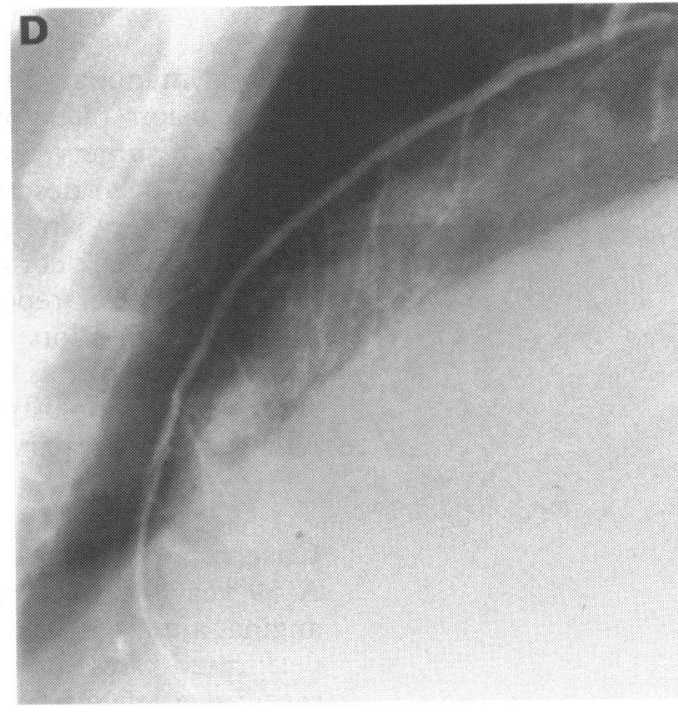

power to cross the occluded segment when braced by the balloon catheter (fig 1B). Secondly the blunt $1 \mathrm{~mm}$ ball tip helps to follow the tortuous course of the mammary artery in a fairly trauma free way. The patient's symptoms were relieved after angioplasty. Ischaemia could still be induced, however, although to a much lesser degree than before angioplasty, as was evident from the improvement in the stress test. That this ischaemia was due to the stenosis of the marginal branch of the left circumflex coronary artery was borne out by the fact that it disappeared after angioplasty of this stenosis.

Recanalisation of chronically occluded internal mammary artery grafts is a technically feasible and clincally successful technique, and it is worthwhile to attempt angioplasty even in patients with such occluded grafts.

1 Singh RN, Sona JA, Green GE. Internal mammary artery versus saphenous venous graft. Comparative perforus Br Heart f 1983;50:48-58.

2 Steffenino GD, Meier B, Finci L, von Segesser L, Velebi $\mathrm{V}$. Percutaneous transluminal angioplasty of right and left internal mammary artery grafts. Chest 1986;90: 849-51.

3 Dimas AP, Arora RR, Whitlow PL, Hollman JL, Franco I, Raymond RE, et al. Percutaneous transluminal angioplasty involving internal mammary artery grafts. $A m$ Heart $\mathcal{F}_{1991 ; 122: 423-9 .}$ 
4 Finci L, Meier B, Steffenino GD. Percutaneous angioplasty of totally occluded saphenous aortocoronary bypass graft. Int f Cardiol 1986;10:76-9.

5 De Feyter PJ, Serruys P, van der Brand M, Meester H Beatt K, Suryapranata H. Percutaneous translumina angioplasty of a totally occluded venous graft: a challenge that should be resisted. Am $\mathcal{F}$ Cardiol 1989;64 88-90.

6 Pande AK, Meier B, Urban P, de la Serna F, Villavicencio $R$, Dorsaz PA. Magnum/Magnarail versus conventional systems for recanalization of chronic total occlusions: randomized comparison. Am Hear 7 1992;123:1182-6.

Tector AJ, Schmahl TM, Canino VR, Kallies JR, Sanfilippo D. The role of the sequential internal mammary artery graft in coronary surgery. Circulation 1984; 70(suppl 1):222-5.

8 Barner HB, Swertz MT, Mudd G, Tyras DH. Late patency of the internal mammary artery as a coronary bypass conduit. Am Thorac Surg 1982;34:408-12.

9 Popma J, Cooke RH, Leon MB, et al. Immediate procedural and long-term clinical results of internal mammary artery angioplasty. Am $\mathcal{f}$ Cardiol 1992;69:1237-9.

10 Shimshak TM, Giorgi LV, Johnsin WL, et al. Application of percutaneous transluminal coronary angioplasty to the internal mammary ärtery graft. $\mathcal{F} \mathrm{Am}$ Coll Cardio 1988;12:1205-14.

11 Bell MB, Holmes DR, Vlietstra RE, Bresnahan DR Percutaneous transluminal angioplasty of left internal mammary artery grafts, two years' experience with a mammary artery grafts, two years' experience
femoral approach. Br Heart $\mathcal{f} 1989 ; 61: 417-20$. 